\title{
IMPACT OF ACNE VULGARIS ON THE QUALITY OF LIFE
}

\author{
Swathylekshmy J. $L^{1}$, Sabeena Jayapalan ${ }^{2}$
}

1Junior Resident, Department of Dermatology \& Venereology, Government Medical College, Thiruvananthapuram, Kerala. 2Additional Professor, Department of Dermatology \& Venereology, Government Medical College, Thiruvananthapuram.

\section{ABSTRACT}

\section{BACKGROUND}

Acne vulgaris is one of the most common skin diseases worldwide. It affects more than $85 \%$ of adolescents and two-thirds of young adults. Face is the commonest site affected. The discomfort, pain, scarring and associated seborrhoea frequently result in psychosocial morbidity.

Aims- To study the impact on the quality of life of acne patients using Dermatology Life Quality Index (DLQI) questionnaire and to find out the sociodemographic and clinical determinants of DLQI.

\section{MATERIALS AND METHODS}

A hospital based cross-sectional study design was adopted. A structured questionnaire was used to collect sociodemographic and clinical characteristics. Severity of acne was assessed by Global Acne Grading System (GAGS) score and quality of life by DLQI questionnaire. DLQI was expressed as mean, and student's t test, one way ANOVA and Pearson's correlation coefficients were used as the tests of significance.

\section{RESULTS}

Acne affected the quality of life in $94 \%$ of patients. Small effect on the quality of life was seen in $37 \%$, moderate effect in $31 \%$ and large effect in $25 \%$ and extremely large effect in $1 \%$. Statistically significant $(\mathrm{P}<0.001)$ correlation was seen between the quality of life and severity of acne. The difference in mean DLQI of patients with and without seborrhoea was statistically significant $(\mathrm{P}=0.045)$.

\section{CONCLUSION}

Acne has an impact on the quality of life of patients. Quality of life measure helps to identify patients who are vulnerable to psychological complications. A quality of life measure can be incorporated as an integral part of acne management.

\section{KEYWORDS}

Acne Vulgaris, DLQI, Quality of Life, QoL, GAGS.

HOW TO CITE THIS ARTICLE: Swathylekshmy JL, Jayapalan S. Impact of acne vulgaris on the quality of life. J. Evolution Med. Dent. Sci. 2017;6(35):2865-2868, DOI: 10.14260/Jemds/2017/618

\section{BACKGROUND \\ Acne vulgaris is one of the ten most common diseases worldwide, affecting all ethnicities and race. The highest prevalence occurs in adolescence, where it occurs in more than $80 \%$. It also affects two-thirds of adults above the age of eighteen. ${ }^{1}$ Acne has a prolonged course with acute or insidious relapse and recurrences. Clinical presentations include non-inflammatory and/or inflammatory lesions associated with pain, discomfort and seborrhoea. Face is the most common site affected and scarring can develop if treatment is delayed. Facial appearance is an important aspect of one's perception of body image. Adolescence is a psychologically labile period when the adolescents usually have a desire to look their best. ${ }^{2}$}

Financial or Other, Competing Interest: None

Submission 25-03-2017, Peer Review 17-04-2017,

Acceptance 24-04-2017, Published 01-05-2017.

Corresponding Author:

Dr. Sabeena Jayapalan

Additional Professor,

Department of Dermatology \& Venereology,

Government Medical College,

Thiruvananthapuram,

Kerala, India

E-mail: sabinajayapalan@gmail.com

DOI: $10.14260 /$ jemds $/ 2017 / 618$

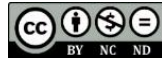

Even though the disease is considered as a part of normal physiological change, the impact on the patients' psyche can be a matter of grave concern. Low self-esteem, low selfconfidence and social dysfunction leading to anxiety, depression, anger and sometimes suicidal ideation has been reported in acne patients. ${ }^{3,4}$ Cosmetic and psychological disability can interfere with career opportunities. Quality of life (QoL) measures help to identify those patients who are vulnerable to psychosocial complications. Knowledge on the impact of acne on the quality of life can bring about a paradigm shift in the management of patients. As such studies have not been conducted in our part of the state, we decided to study the quality of life in our acne patients, the proportion of patients with an effect on the quality of life and the sociodemographic and clinical characteristics that determine the quality of life.

\section{MATERIALS AND METHODS}

Acne patients above the age of 11 years attending the Department of Dermatology and Venereology of a tertiary care centre in South Kerala were studied after getting informed written consent. Non-consenting patients and patients with chronic dermatological and non-dermatological comorbidities that can adversely affect the quality of life were excluded. A hospital based, cross-sectional descriptive type of study design was used. Using the sample size formula, $4 \mathrm{pq} / \mathrm{L}^{2}$, where ' $\mathrm{p}$ ', the proportion of patients with an effect on 
the quality of life was set as $81 \%$ based on an Indian study, ${ }^{3}$ ' $q$ ', the proportion without an effect on the quality of life as 19 and ' $L$ ', $10 \%$ of ' $p$ ' as 8.1 , the minimum sample size was calculated to be 93. Structured questionnaire was used to collect the data under the broad domains of sociodemographic characteristics and disease characteristics. The severity of acne was assessed by the Global Acne Grading system (GAGS). ${ }^{5}$ Quality of life was assessed by the Dermatology Life Quality Index (DLQI) questionnaire for patients above the age of 16 and by Children's Dermatology Life Quality Index (CDLQI) questionnaire for patients less than 16 years of age. 6,7,8 Formal permission from Department of Dermatology, Cardiff University was obtained to use DLQI/CDLQI questionnaire. The questionnaire was answered by the patients themselves and children answered with the help of their guardian. The DLQI/CDLQI score was calculated by us. Data were entered in Excel and analysed by appropriate software (Excel and Epi Info 7). DLQI was the outcome variable and the independent variables were sociodemographic characteristics (age, gender, income, occupation and marital status) and disease characteristics (age of onset, seborrhoea, aggravating factors, site, morphology and severity of acne). DLQI was expressed as mean. For analysis, age was categorised into five groups (11$15,16-20,21-25,26-30,>30$ ), occupation into two (skilled/professional, unskilled/home maker), age of onset into three groups $(10-15,16-20,>20$ years), duration of acne three $(<1,1-4, \geq 5$ years) and severity into three groups (mild, moderate, severe). Student's t test, one way analysis of variance (ANOVA) and Pearson's correlation coefficient used as the test of significance.

\section{RESULTS}

The DLQI of one hundred acne patients attending the Department of Dermatology and Venereology of a tertiary care centre in South Kerala were studied.

Majority of the patients were female (67\%) and the rest were male (33\%). Age ranged from 12 to 45 years (mean$21.3 \pm 5.4$; males- $20.6 \pm 6.5$; females- $21.6 \pm 4.9$ ). The maximum number (44\%) belonged to the 16-20 age group incorporating majority of both males (54.5\%) and females (38.8\%). $75 \%$ of the patients were students $(78.8 \%$ males; $73.1 \%$ females) followed by homemakers (18\%) and professionals (7\%). 76\% were unmarried $(81.8 \%$ males; $73.1 \%$ females) and $24 \%$ married.

The age of onset of acne ranged from 12 to 36 years (mean -17.7 \pm 4.3 ; males- 17.1; females-18.1). The duration of the disease ranged from 2 weeks to 17 years (mean-3.7 \pm 4.2 years; males- $2.7 \pm 2.7$; females- $4.2 \pm 4.7$ ). Duration of majority $(48 \%)$ was between $1-4$ years. Seborrhoea was observed in $59 \%$ ( $66.7 \%$ males; $55.2 \%$ females). $54 \%$ of patients had at least one aggravating factor and multiple aggravating factors in $29.6 \%$. Diet was the most common aggravating factor in males and in females it was menstruation. Most of the patients presented with lesions on multiple sites with face as the commonest site followed by chest and upper back. Different morphological types of lesions were present at the time of examination in majority of the patients. Papule was the commonest (99\%) followed by comedones (85\%). Nodules (60.6\%), scarring (21.2\%) and post-inflammatory hyperpigmentation $(66.7 \%)$ were more common in males. Based on GAGS score, $55 \%$ of patients had mild acne, 38\% had moderate acne and $7 \%$ had severe acne. Mild acne was more in females $(72.7 \%)$ whereas severe acne was more in males (71.4\%). The GAGS score ranged from 1 to 36 (mean $-18.7 \pm 6.8$; males $-21.2 \pm 7.3$; females $-17.5 \pm 6.1$ ).

Acne affected the quality of life in $94 \%$ of patients (Table I). Symptoms of the disease and embarrassment affected the quality of life in $84.8 \%$, daily activities were affected in $56.7 \%$, leisure activities in $58.4 \%$, personal relationships were compromised in $40.6 \%$ and loss of time by treatment in $52.2 \%$. Acne prevented $29 \%$ patients from working/studying. There were 10 children and in them disease symptoms and embarrassment affected the quality of life in $80 \%$, leisure activities in $36.7 \%$, personal relationships compromised in $35 \%$, sleep in $40 \%$, school work in $40 \%$ and loss of time by treatment in $30 \%$. The DLQI score ranged from 0 to 21 (mean- 7.3 \pm 6.8 ; males- 8.4 \pm 5.7 ; females- $6.8 \pm 4.5$ ).

Each independent variable like gender, age, occupation, marital status, duration, site, morphology of lesion and acne severity were grouped and mean DLQI in each group was computed and tested for statistical significance (Table II). Significant difference in the mean DLQI was seen among patients with and without seborrhoea and in the severity grade range of acne. There was a statistically significant difference $(\mathrm{P}=0.045)$ between the mean DLQI in patients with seborrhoea $(8.14 \pm 4.9)$ and in those without seborrhoea $(6.12 \pm 4.9)$. The mean DLQI for mild, moderate, severe acne were $5.76 \pm 4.1,8.50 \pm 5.1$ and $13 \pm 4.8$ respectively. The mean DLQI increased with the severity of acne and this difference in the mean between the three groups was statistically significant $(\mathrm{P}<0.001)$. Pearson's correlation was done to find the correlation between GAGS score and DLQI. There was significant correlation between the severity of acne assessed by GAGS score and DLQI (r- 0.345, p- 0.001). In females, the mean DLQI was $5.05 \pm 3.3,9.04 \pm 4.7$ and $13.50 \pm$ 5 in mild, moderate, and severe acne respectively. The mean DLQI showed higher values with increasing severity and this difference in mean between the three groups was statistically significant ( F 10.923, $\mathrm{P}<0.001)$. There was significant correlation between the severity of acne assessed by GAGS score and DLQI ( $\mathrm{r}-0.413, \mathrm{p}-0.001$ ) in females by the Pearson's correlation method. In males, the mean DLQI in mild, moderate and severe acne were $7.67 \pm 5.3,7.46 \pm 5.9$, $12.80 \pm 5.3$ respectively. Though the mean DLQI was high in patients with severe acne, there was no statistical significant difference between three groups ( $F$ 1.885, P 0.169). There was no significant correlation between the severity of acne assessed by GAGS score and DLQI in males (r-0.300, P- 0.09) by the Pearson's correlation method. Though the mean DLQI differed between groups among gender, age, occupation, age of onset and duration, the difference was not statistically significant.

\begin{tabular}{|c|c|c|c|c|c|c|}
\hline \multirow{2}{*}{ DLQI } & \multicolumn{2}{|c|}{ Male } & \multicolumn{2}{|c|}{ Female } & \multicolumn{2}{|c|}{ Total } \\
\hline & $\mathbf{N}$ & $\%$ & $\mathbf{N}$ & $\%$ & $\mathbf{N}$ & $\%$ \\
\hline No Effect (0-1) & 3 & 9.1 & 3 & 4.5 & 6 & 6.0 \\
\hline Small Effect (2-5) & 10 & 30.3 & 27 & 40.3 & 37 & 37.0 \\
\hline Moderate Effect (6-10) & 8 & 24.2 & 23 & 34.3 & 31 & 31.0 \\
\hline Very Large Effect (11-20) & 11 & 33.3 & 14 & 20.9 & 25 & 25.0 \\
\hline $\begin{array}{c}\text { Extremely Large Effect } \\
(21-31)\end{array}$ & 1 & 3.0 & 0 & 0.0 & 1 & 1.0 \\
\hline Total & 33 & 100.0 & 67 & 100.0 & 100 & 100.0 \\
\hline
\end{tabular}




\begin{tabular}{|c|c|c|c|c|c|c|}
\hline \multirow{2}{*}{\multicolumn{2}{|c|}{ Variables }} & \multirow{2}{*}{$\mathbf{n}$} & \multicolumn{2}{|c|}{ DLQI } & \multirow{2}{*}{$t / F$} & \multirow{2}{*}{$P$} \\
\hline & & & \multirow{2}{*}{\begin{tabular}{|c|} 
Mean \\
67
\end{tabular}} & \multirow{2}{*}{$\begin{array}{l}\text { SD } \\
5.4\end{array}$} & & \\
\hline \multirow{5}{*}{ Age } & $11-15$ & 10 & & & \multirow{5}{*}{$0.45^{*}$} & \multirow{5}{*}{0.77} \\
\hline & $16-20$ & 44 & 8.1 & 5.4 & & \\
\hline & $21-25$ & 29 & 6.6 & 4.8 & & \\
\hline & $26-30$ & 10 & 6.7 & 3.8 & & \\
\hline & $>30$ & 7 & 7.3 & 4.3 & & \\
\hline \multirow{2}{*}{ Gender } & Male & 33 & 8.4 & 5.7 & \multirow{2}{*}{$1.504 \dagger$} & \multirow{2}{*}{0.14} \\
\hline & Female & 67 & 6.8 & 4.5 & & \\
\hline \multirow{3}{*}{ Occupation } & Student & 75 & 6.9 & 4.8 & \multirow{3}{*}{$2.53^{*}$} & \multirow{3}{*}{0.08} \\
\hline & $\begin{array}{c}\text { Skilled/ } \\
\text { Professional }\end{array}$ & 7 & 11.3 & 6.3 & & \\
\hline & $\begin{array}{c}\text { Unskilled/ } \\
\text { Home Maker }\end{array}$ & 18 & 7.2 & 4.8 & & \\
\hline \multirow{3}{*}{$\begin{array}{c}\text { Age } \\
\text { of onset }\end{array}$} & $10-15$ & 40 & 6.8 & 4.6 & \multirow{3}{*}{$0.519^{*}$} & \multirow{3}{*}{0.59} \\
\hline & 16-20 & 43 & 7.9 & 5.4 & & \\
\hline & $>20$ & 17 & 7.2 & 4.6 & & \\
\hline \multirow{3}{*}{$\begin{array}{l}\text { Duration } \\
\text { of Acne }\end{array}$} & $<1$ year & 27 & 8.1 & 4.1 & \multirow{3}{*}{$0.634^{*}$} & \multirow{3}{*}{0.53} \\
\hline & 1-4 years & 68 & 6.9 & 5.3 & & \\
\hline & $>5$ years & 5 & 8.2 & 4.9 & & \\
\hline \multirow{2}{*}{ Seborrhoea } & Yes & 59 & 8.1 & 4.9 & \multirow{2}{*}{$2.033 \dagger$} & \multirow{2}{*}{$0.04 \ddagger$} \\
\hline & No & 41 & 6.1 & 4.9 & & \\
\hline \multirow{3}{*}{$\begin{array}{l}\text { Severity } \\
\text { of Acne }\end{array}$} & Mild & 55 & 5.8 & 4.1 & \multirow{3}{*}{$9.933^{*}$} & \multirow{3}{*}{$0.001 \ddagger$} \\
\hline & Moderate & 38 & 8.5 & 5.1 & & \\
\hline & Severe & 7 & 13 & 4.8 & & \\
\hline \multicolumn{7}{|c|}{$\begin{array}{l}\text { SD- Standard Deviation, t- t Statistic of Student's t Test, F -F } \\
\text { Ratio of One way } \\
\text { ANOVA, P-Level of Significance, }{ }^{*} \text { F Value, } † \text { Value of } t \text { Test, ₹ } \\
\text { Significant p Value }\end{array}$} \\
\hline & $\begin{array}{l}\text { able II. Anal] } \\
\text { DLQI and In }\end{array}$ & & tis & & & \\
\hline
\end{tabular}

\section{DISCUSSION}

WHO defines quality of life as the individual's perception of their position in the context of culture and value systems in which they live and in relation to their goals, expectations, standards, and concerns. Acne, though neither life threatening nor physically debilitating can affect psychological and social functioning and can adversely affect the quality of life. Measurement of quality of life can be done through validated questionnaires. Dermatology specific questionnaires include DLQI, Skindex and dermatology quality of life scales (DQOLS). Acne-specific measures include acne disability index (ADI), Cardiff acne disability index (CADI), assessment of the psychological and social effects of acne (APSEA), and acne quality of life (AQOL). ${ }^{9}$ DLQI was the first dermatology specific health related questionnaire that was simple and could be accurately and rapidly completed by patients without supervision. ${ }^{6}$ It has been widely used in psoriasis, atopic dermatitis, acne and chronic urticaria and over 36 different dermatological conditions. Validated translations are available in regional Indian languages. Hence, we preferred DLQI rather than other acne specific indices for measuring quality of life.

The concern regarding the appearance and disease might have contributed to the female predominance in our study as in other studies. 4,10 There are also contradictory reports with male predominance or equal representation of both sexes.11,12 The males and females did not differ significantly in the mean age and the commonest age group and was similar to studies from India and Iran.3,10,13 Like in other studies, majority were students and were unmarried.12,13 The mean age of onset of 17.7 years was higher when compared to a South Indian study even though both studies were similar in the early mean age of onset in males. ${ }^{14}$ Similar to several studies, the duration of acne was between 1-4 years in majority (48\%) in our study.3,15,16 59\% of our patients had seborrhoea and it was more in males similar to a report from Thailand.17Aggravating factors were present in 54\% with multiple aggravating factors in $29.6 \%$. Premenstrual flare was the most common aggravating factor in females as in other reports.3,18 Majority of patients presented with different morphological types of lesions and papules, comedones and pustules were the commonest as observed in other studies. ${ }^{14,19} \mathrm{As}$ reported in literature, severe forms like scarring and nodules were common in males. ${ }^{10,11,14,20}$ The less severe morphological type of lesions in females could be explained by the early treatment and better compliance with treatment due to cosmetic concerns.

The quality of life was compromised in $94 \%$ of the patients. $37 \%$ had small effect, $31 \%$ had moderate effect, $25 \%$ had very large effect and only $1 \%$ had extremely large effect. There are studies with comparable DLQI scores and mean DLQI.12 Less gender discrimination, high level of literacy and non-domestic employment in our state could explain the lack of statistically significant difference in the mean DLQI score in both males and females when compared to an Egyptian study where there was a significant difference, explained by the fact of women staying at home and covering their face, making them less exposed than men to social embarrassment. ${ }^{21}$ Across age groups and occupation categories, there was no significant difference in mean DLQI, though the mean DLQI was high in professional and skilled labourers. The significance level of P 0.08 in the occupation category indicated that this could have been significant if the sample size was more as there were only 7 patients in the professional group. Comparable and contradictory findings have been reported in literature.12,21,22, 23,24 Early age of onset can affect the DLQI and there are reports with statistically significant positive correlation between duration of acne and DLQI score. ${ }^{21}$ Though the mean DLQI was high in our patients with disease duration $\geq 5$ years, the difference did not achieve statistical significance due to the less number of patients in this subgroup. There was a significant difference ( $P$-0.045) in the mean DLQI in acne patients with and without seborrhoea. Severe acne was observed in our patients with seborrhoea. The role of sebum in the pathogenesis of acne is well known. ${ }^{1}$ It may not be the seborrhoea per se, that caused a significant difference in the quality of life, but the severe acne lesions due to seborrhoea. Seborrhoea might have acted as a confounder for acne severity.

The single most important determinant of the quality of life was disease severity. The DLQI scores increased with increasing severity of acne as assessed by the GAGS score $(\mathrm{P}<$ 0.001). Positive correlation between disease severity and quality of life scores has been reported, though some studies use different tools to grade disease severity and quality of life.11,12,20,21,23,25 When the data was analysed separately for both males and females, there was a significant correlation ( $P$ $<0.001$ ) between disease severity and quality of life in the case of females whereas there was no correlation (P-0.09) in the case of males. Males constituted only $33 \%$ of the study population and when these males were categorised further based on disease severity, the number in each group became less and this could explain the absence of positive correlation 
between disease severity and quality of life even though the mean DLQI score was highest in males with severe acne.

The sample size was adequate for the assessment of quality of life of acne patients in general but was inadequate when the patients were grouped based on gender, age, occupation, age of onset, duration, disease severity, etc. Though the findings are comparable to other reported studies, it lacks generalizability due to the tertiary care setting. The selection of the quality of life assessment tool might have influenced the quality of life score. The tool used for assessing quality of life in this study was a time tested DLQI questionnaire instead of acne specific questionnaires.

\section{CONCLUSION}

Acne vulgaris is not a life-threatening disease, but it has definite implications on the quality of life. The fact that this disease affected the quality of life in $94 \%$ of our patients is a matter of grave concern. Majority of them were students and youngsters pursuing career opportunities. An adverse influence of acne on the daily activities, symptoms and feelings, personal relationships, leisure activities, studies and work place can cause emotional and psychiatric disturbances which in turn can affect the quality of life and a vicious cycle sets in. Many, especially adults, do not consider it as a problem worth treating and consider acne as a part of normal growing up. The single most important determinant of quality of life in our study was disease severity. Severity of the disease is the consequence of lack of proper treatment. The public should be made aware of the significant psychosocial consequences underlying the simple cosmetic problem called acne and the importance of early treatment. Increased awareness and early intervention can reduce the negative impact on the psychosocial domains of life. In addition to appropriate pharmacological treatment, the dermatologist should also incorporate quality of life assessment measures to identify the vulnerable cases, provide help and support to those in need.

\section{REFERENCES}

[1] Layton AM, Eady A, Zouboulis CC. Acne. In: Griffiths C, Barker J, Bleiker T, et al. (eds). Rook's textbook of dermatology. $9^{\text {th }}$ edn. John Wiley and sons Ltd 2016:90.1-90.64.

[2] Pruthi GK, Babu N. Physical and psychosocial impact of acne in adult females. Indian $\mathrm{J}$ Dermatol 2012;57(1):26-9.

[3] Samanthula H, Kodali M. Acne and quality of life- a study from a tertiary care centre in South India. IOSRJDMS 2013;6(3):59-62.

[4] Khunger N, Kumar C. A clinico-epidemiological study of adult acne: is it different from adolescent acne? Indian J Dermatol Venereol Leprol 2012;78(3):335-41.

[5] Doshi A, Zaheer A, Stiller MJ. A comparison of current acne grading systems and proposal of a novel system of a novel system. Int J Dermatol 1997;36(6):416-8.

[6] Finlay AY, Khan GK. Dermatology life quality index (DLQI)-a simple practical measure for routine clinical use. Clin Exp Dermatol 1994;19(3):210-6.

[7] Finlay AY, Lewis-Jones MS. The children's dermatology life quality index (CDLQI): initial validation and practical use. Br J Dermatol 1995;132(6):942-9.

[8] Finlay AY. Quality of life indices. Indian J Dermatol Venereol Leprol 2004;70(3):143-8.
[9] Kubba R, Bajaj AK, Thappa DM, et al. Acne in India: guideline for management- IAA consensus document. Indian J Dermatol Venereol Leprol 2009;75(Suppl 1):1-62.

[10] Singh A, Agarwal P, Choudhary SV, et al. Disability in acne patients-a hospital based study in rural population of central India. Global Journal of Dermatology \& Venereology 2013;1(2):21-4.

[11] El-Khateeb EA, Khafagy NH, Elaziz AK, et al. Acne vulgaris: prevalence, beliefs, patients attitudes, severity and impact on quality of life in Egypt. Public Health 2014;128(6):576-8.

[12] Durai PCT, Nair DG. Acne vulgaris and quality of life among young adults in South India. Indian Journal of Dermatology 2015;60(1):33-40.

[13] Ghaderi R, Saadatjoo A, Ghaderi F. Evaluating of life quality in patients with acne vulgaris using generic and specific questionnaires. Dermatology Research and Practice 2013;2013:1-6.

[14] Thappa DM, Adityan B. Profile of acne vulgaris-a hospital-based study from South India. Indian J Dermatol Venereol Leprol 2009;75(3):272-8.

[15] Jankovic S, Djordjevic S, Marinkovic J, et al. Quality of life among schoolchildren with acne: results of a crosssectional study. Indian J Dermatol Venereol Leprol 2012;78(4):454-8.

[16] Lasek RJ, Chren MM. Acne vulgaris and the quality of life of adult dermatology patients. Arch Dermatol 1998;134(4):454-8.

[17] Kulthanan K, Jiamton S, Kittisarapong R. Dermatology life quality index in Thai patients with acne. Siriraj Med J 2009;59:3-7.

[18] Lucky AW. Quantitative documentation of a premenstrual flare of facial acne in adult women. Arch Dermatol 2004;140(4):423-4.

[19] Gieler U, Gieler T, Kupfer JP. Acne and quality of lifeimpact and management. Journal of the European Academy of Dermatology and Venereology 2015;29(4):12-4.

[20] Kokandi A. Evaluation of acne quality of life and clinical severity in acne female adults. Dermatology Research and Practice 2010;2010:1-3.

[21] Abdel-Hafez K, Mahran AM, Hofny ER, et al. The impact of acne vulgaris on the quality of life and psychologic status in patients from upper Egypt. Int J Dermatol 2009;48(3):280-5.

[22] Yazici K, Baz K, Yazici AE, et al. Disease-specific quality of life is associated with anxiety and depression in patients with acne. Journal of the European Academy of Dermatology and Venereology 2004;18(4):435-9.

[23] Berg M, Lindberg M. Possible gender differences in the quality of life and choice of therapy in acne. Journal of the European Academy of Dermatology and Venereology 2010;25(8):969-72.

[24] Ismail KH, Mohammed-Ali KB. Quality of life in patients with acne in Erbil city. Health and Qual Life Outcomes 2012;10:60.

[25] Yap FB. The impact of acne vulgaris on the quality of life in Sarawak, Malaysia. Journal of the Saudi Society of Dermatology \& Dermatologic Surgery 2012;16(2):57-60. 